\title{
Pediatricians as Medical-Educational Brokers for Children of Deaf Parents
}

\author{
Michelle Curtin DO FAAP ${ }^{1,2 *}$ and Kristin Wikel Med ${ }^{2}$ \\ ${ }^{1}$ Department of Pediatrics, Indiana University School of Medicine, Indiana \\ ${ }^{2}$ Riley Hospital for Children, Indiana
}

Submission: July 26, 2021; Published: August 09, 2021

*Corresponding author: Michelle Curtin DO, Department of Pediatrics, Indiana University School of Medicine, 1002 Wishard Blvd, Suite 3120, Indianapolis IN 46202, Indiana

Abstract

We present a case in which a school system and the family of a typically hearing child of deaf adults (CODA) were in disagreement about school eligibilities, educational interventions, and medical needs. Subsequently consultation was requested to help with clarification of medical and educational needs following family request for support with their primary care provider (PCP). This case raises unique cultural considerations that may be encountered by PCP caring for CODAs in their practices. Patients will often present to PCP with concerns of academic underachievement or failure. The family benefitted from engagement with the medical community, who provided the parents with education on the patient's school eligibility, translated educational information into medical diagnoses where appropriate (e.g., Intellectual Disability, Expressive Language Disorder), offered medical recommendations for further evaluation/optimization of care, and served as liaisons between the family and school.

Keywords: Deaf adults; Language disorder; Educational interventions; Cognitive disability; Intellectual disability

Abbreviations: ABAS-III: Adaptive Behavior Assessment System; ASL: American Sign Language; CPIR: Center for Parent Information and Resources; CODA: Child of deaf adults; FSIQ: Full Scale Intelligence Quotient; English Learners/EL: English is a second language; IEP: Individualized Education Program; PCP: Primary Care Providers; WISC-V: Wechsler Intelligence Scale for Children

\section{Introduction}

Students for whom English is a second language (English Learners/EL) comprise $10 \%$ of K-12 students in the United States. We present a case in which a school system and the family of a typically hearing child of deaf adults (CODA) were in disagreement about school eligibilities, educational interventions, and medical needs [1]. "Eligibilities" represent areas wherein the student could qualify to be considered for school services. Subsequently consultation was requested to help with clarification of medical and educational needs following family request for support with their primary care provider [2]. This case raises unique cultural considerations that may be encountered by PCP caring for EL/ CODAs in their practices. Here forward, the patient is referred to as "the student."

\section{Case}

An 11-year-old CODA who communicates exclusively with American Sign Language (ASL) at home and has access exclusively to spoken English at school was seen in subspecialty medical consultation. Medical chart review demonstrated that a school hearing screen at entry into the educational system ( $<6$-years) was failed, follow up audiological evaluation subsequently showed normal hearing ability bilaterally.

At school the student was served by an Individualized Education Program (IEP) under an eligibility of "Cognitive Disability," which the team reviewed as part of intake [3]. This eligibility had not been shared previously within the medical system and the PCP did not have a record of this concern. Due to the eligibility, the student's academic placement was outside of the local school, where the other siblings received their instruction. Parents questioned the accuracy of the school evaluation, which they believed underestimated the patient's abilities, and this "label" on the IEP. They additionally requested an ASL interpreter be present at school in the class setting for all educational activities, hoping this adjustment could assist the patient's understanding/ learning and give a clearer picture of the student's overall skills and functioning. The school deemed an ASL interpreter to be an inappropriate accommodation, since the student had normal hearing on audiological evaluation. They additionally contested 
that the student had no language needs related to spoken English proficiency in the classroom setting. A strained relationship subsequently developed between the family and school team.

Parents were uncertain of where to obtain assistance in light of the disagreement. At a well child visit, they expressed concerns to the PCP about school accommodations secondary to limited academic progress, prompting referral to this subspecialty clinic. Medical history including development, behavior, and academic progress, physical exam, medical evaluation records, and previous cognitive testing were reviewed as part of that appointment [4].

The subsequent plan which was developed based on those results included:

a) Review of the school eligibility including definition and criteria, current educational supports in place, and overall case concerns with the student's family.

b) Coordination of updated, secondary assessment to determine the student's cognitive and spoken English skills with appropriate individuals in child psychology and speech-language pathology.

c) Finally, the family was connected to their local, schoolbased advocate through the national Center for Parent Information and Resources (CPIR) [5].

Updated assessment demonstrated a Full Scale Intelligence Quotient (FSIQ) of 42 on Wechsler Intelligence Scale for Children (WISC-V) was consistent with Moderate Intellectual Disability as well as depressed adaptive skills on family completed Adaptive Behavior Assessment System (ABAS-III). This FSIQ was consistent with the previous school assessment and the IEP eligibility of Cognitive Disability. Speech-Language testing demonstrated a score that was significantly depressed compared to the student's age, qualifying for an additional diagnosis of mixed receptiveexpressive language disorder. Subsequently, a plan of treatment across medical and educational arenas was discussed with the family. This included medical recommendations to evaluate for a possible underlying etiology of and to address the associated needs of the diagnoses of Intellectual Disability and mixed receptiveexpressive language disorder [6]. With the support of the CPIR, the recommendations and family needs were discussed with the school, including consideration of appropriate interventions at the school the siblings were attending, so that all of the siblings could be at the same school location.

Medical-educational interventions included: initiation of first tier genetic testing, optimization of the student's self-care independence with initiation of both school and outpatient-based occupational therapy, intervention with both schooland outpatientbased speech therapy, Alternative/Augmentative Communication support via ASL in light of her comfort, and planning for transitions to adulthood (e.g., vocational rehabilitation, healthcare financing).

\section{Discussion}

Patients will often present to PCP with concerns of academic underachievement or failure. Given parents' exclusive reliance on ASL, ASL is the patient's native language, making her an EL student who might benefit from EL supports. The family benefitted from engagement with the medical community, who provided the parents with education on the patient's school eligibility, translated educational information into medical diagnoses where appropriate (e.g., Intellectual Disability, Expressive Language Disorder), offered medical recommendations for further evaluation/optimization of care, and served as liaisons between the family and school. More information on supporting CODA students can be found with Children of Deaf Adults International, Inc. (http://www.coda-international.org) [7].

\section{Contributor's Statement}

Both authors contributed to all steps in development of this case report.

\section{References}

1. Moroe NF, de Andrade V (2018) Hearing children of Deaf parents: Gender and birth order in the delegation of the interpreter role in culturally Deaf families. Afr J Disabil 7: 365.

2. Luterman DM, Chasin J (1970) The pediatrician and the parent of the deaf child. Pediatrics 45(1): 115-116.

3. Lipkin PH, Okamoto J, Council on Children with Disabilities, Council on School Health (2015) The Individuals With Disabilities Education Act (IDEA) for Children With Special Educational Needs. Pediatrics 136(6): e1650-e1662.

4. Rey-Casserly C, McGuinn L, Lavin A, Committee on psychosocial aspects of child and family health, Section on developmental and behavioral pediatrics (2019) School-aged Children Who Are Not Progressing Academically: Considerations for Pediatricians. Pediatrics 144(4): e20192520.

5. Center for Parent Information \& Resources, U.S. Department of Education, Office of Special Education Programs No. H328R180005.

6. Moeschler JB, Shevell M (2014) Committee on Genetics. Comprehensive evaluation of the child with intellectual disability or global developmental delays. Pediatrics 134(3): e903-e918.

7. Children of Deaf Adults International. 

This work is licensed under Creative
Commons Attribution 4.0 License
DOI: $10.19080 / J O J C S .2021 .12 .555842$
Your next submission with Juniper Publishers will reach you the below assets

- Quality Editorial service

- Swift Peer Review

- Reprints availability

- E-prints Service

- Manuscript Podcast for convenient understanding

- Global attainment for your research

- Manuscript accessibility in different formats ( Pdf, E-pub, Full Text, Audio)

- Unceasing customer service

Track the below URL for one-step submission https://juniperpublishers.com/online-submission.php 